\title{
Wind Energy Assessment at Bafoussam, Cameroon
}

\author{
Talla Pierre Kisito ${ }^{1}$, Bawe Gerard Nfor, $\mathrm{Jr}^{1}$, Yemele David ${ }^{1} \&$ Ghogomu Patrick Ndinakie ${ }^{1}$ \\ ${ }^{1}$ Department of Physics, University of Dschang, Dschang, West Region, Cameroon \\ Correspondence: Bawe Gerard Nfor, Jr, Department of Physics, University of Dschang, P. O. Box 67, Dschang, \\ West Region, Cameroon. Tel: 237-67-526-3613. E-mail: nforbawe@yahoo.com
}

Received: August 8, 2015 Accepted: August 21, 2015 Online Published: November 23, 2015

doi:10.5539/jsd.v8n9p106

URL: http://dx.doi.org/10.5539/jsd.v8n9p106

\begin{abstract}
Three-hourly wind speed data measured using the Beaufort scale at a height of $10 \mathrm{~m}$, from $6 \mathrm{am}$ to $6 \mathrm{pm}$ local time ( 5 periods per day), was obtained from the Bafoussam Airport. It was analyzed using the Weibull and Rayleigh probability density models and wind rose plots. It was determined that the lowest wind speeds (most calms) were observed during the first period (6am) and the highest at 3pm (fourth period). The very low morning wind speed adversely affected the daily mean wind speed. Better, but still poor, power density results were obtained at this fourth $(3 \mathrm{pm})$ period. The monthly and yearly mean speeds varied between 1.9 and $3.1 \mathrm{~m} / \mathrm{s}$ and with very low standard deviations. The wind rose plots also showed that all the significant winds fell in the first quadrant (NE) and predominantly on angle $10^{\circ}$ with some discernibly on $20^{\circ}$ and $30^{\circ}$, only. Three goodness-of-fit tests: the chi square, coefficient of determination or $\mathrm{R}^{2}$ and root mean square error, showed the Weibull to be a better fit to the wind regime than the Rayleigh model. The shape parameters were always greater than the scale parameters. Results show that, using the Weibull parameters, the power density of Bafoussam falls in the category 1 of the wind energy resource group and hence is not a very good wind energy exploitable candidate.
\end{abstract}

Keywords: Beaufort scale, 3-hourly winds, Weibull, wind rose, Bafoussam, power density

\section{Introduction}

Mankind's crave for energy is insatiable due to ever increasing population and industries. This is relatively easily achieved with fossil fuels. Unfortunately, this major source has been held responsible for many undesirable effects such as the depletion of the ozone layer; global warming, and many environmental degradation concerns. Hence, one of the greatest challenges is to explore ways of reducing the emissions of greenhouse gases into the atmosphere, which potentially could at least slow down the process of global warming and other surface environmental negative effects. Consequently, we need to investigate sources of renewable and clean energy that are environmentally friendly and abundantly sustainable. Wind, among others, is such a potential candidate.

Basically, wind energy is an indirect form of solar energy; it is generated by uneven heating of the earth's surface that creates pressure gradients due to temperature differences as given by M, Sathyajith (2006).

Wind speed is the most important aspect of the wind resource. In fact, Aynuar and Figen (2008), showed that the yearly and seasonal variation of long term mean wind speed provides an understanding of the long term pattern of wind speed and also gives confidence to an investor on the availability of wind power in coming years. Many of such endeavours have been going on in various regions and countries around the world, Africa, in particular, included. To estimate wind mean power density, which is one of the preliminary information of installing feasible wind farms, statistical investigations have been performed in Rwanda, Safari and Gasore (2010). Adaramola and Oyewola (2011) carried out an intensive study on the detailed measurements on wind speed, direction, temperature and the nature of the topology of a site on a targeted site in Nigeria over a defined period and were able to identify areas that are suitable for exploitation of wind energy for electricity generation as well as for water pumping.

Nfah, Ngundamb, Vandenbergh and Schmid (2008) provide a vivid description of the energy potential, problems and consequences in Cameroon. With a huge hydroelectric potential of (294 TWh), and occupying a prestigious position as the second largest in Africa, after the DR Congo (1000 TWh), Cameroon still suffers from severe energy crisis: very frequent power outages and rampant low tension; particularly during the evenings. This is particularly witnessed during the dry season: January to April. This greatly stalls grid connected activities, whose 
connectivity is just about $11 \%$. This lead to the installation of thermal plants but the ever growing population and more energy demanding structures and activities has still not decreased the crisis.

If viable, small scale off-grid installations may curb this debility if local renewable sources are identified and properly harnessed. Among these local sources are organic wastes, solar and wind. As far as wind energy potential studies in Cameroon are concerned, only her northern part of the national territory is fairly covered in the literature. Tchinda and Kaptouom (2003) estimated the mean wind power in the far north province. In another study, Tchinda, Kendjio, Kaptouom, Njomo (2014) analysed wind speed and wind energy distributions in the Adamaoua and North regions. Kaoga, Sergeb, Raidandic, Djongyang (2014), Kaoga, Danwe, Yamigno, Djongyang (2014), Kaoga,, Djongyang, Doka, Raidandi (2014), Kaoga1, Raidandi, Djongyang, Doka, (2014) equally and variously carried out wind energy studies in Kousseri, Maroua and Garoua, all from the northern regions. Their studies showed that the region is not feasible for wind energy exploitation but feasible as water wind mills. In the southern part of Cameroon, only a single case is documented in the literature. Using NASA data, Afungchui and Aban (2014) carried out studies of Bamenda's environ and determined that the wind regime is Weibull representative and hence could be used to model the power density of this locality. However, Satellite data, in general, is always of low resolution albeit indicative of the tendency of wind regime.

In this work we study the wind characteristics of Bafoussam, also in the southern part of Cameroon and about $80 \mathrm{~km}$ from Bamenda. It is a regional headquarter (of the West Region), heavily populated and with many agro-industrial activities and medium sized industries and structures and, hence, inherently exposed to the same energy demise. In this paper we study the wind characteristics based on the Weibull and Rayleigh probability distribution models and evaluate wind energy potential application of any windmill. We use three goodness-of-fit (gof) tests to discriminate which of the two models best fits the wind regime at this site. Furthermore, we also determine the wind speed classes and the dominant wind directions at this site. Wind directions are important in determining the directions in which the blades of a vertical axis turbine should be facing so as to minimize the wear and tear when turning to face its direction or during furling.

\section{Site Description and Data}

Bafoussam is situated on latitude 5.5, longitude 10.4 and at an altitude $1438 \mathrm{~m}$ and on the Bamboutous highland. The 3-hourly periodically measured daily wind speed data used in this study was obtained from the Bafoussam Airport, Fig.1, for the period 2007 to 20013 spanning a duration of seven years. The wind speed data was measured using the Beaufort scale at an altitude of $10 \mathrm{~m}$ above the ground.

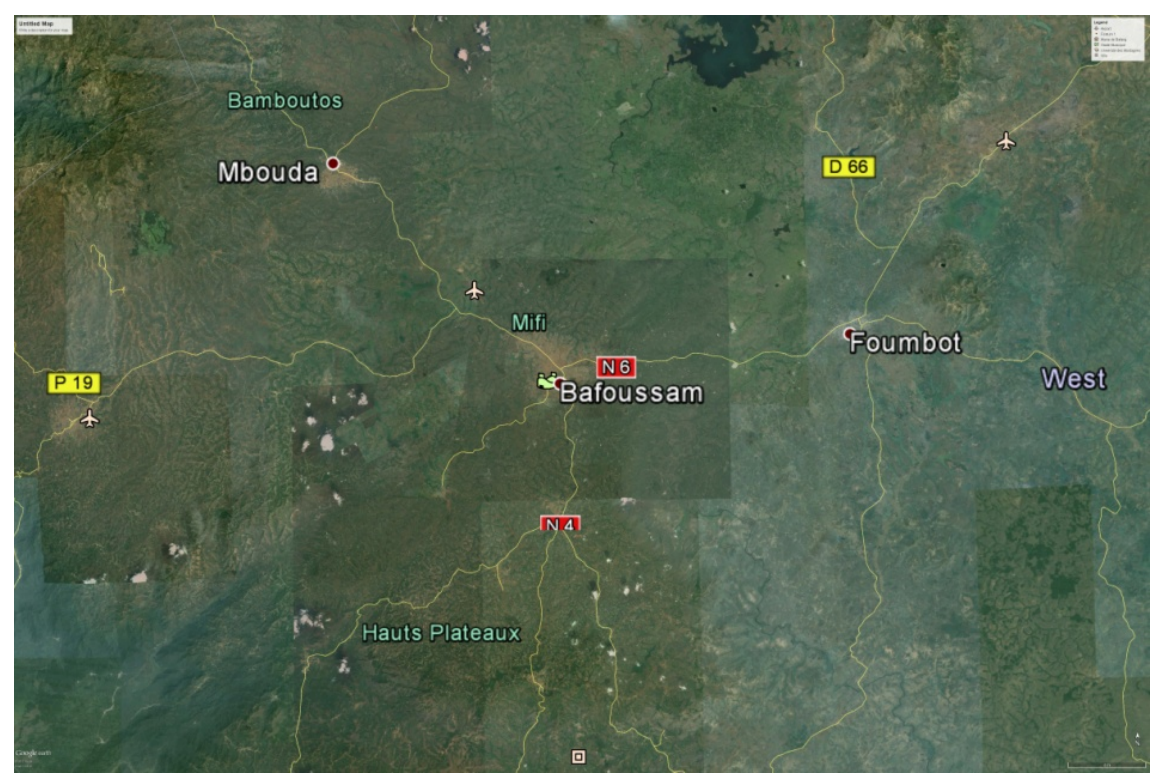

Figure 1. Google Map of Bafoussam showing the location of its airport, which is NW of the town

\subsection{Data Preprocessing}

\subsubsection{Weibull and Rayleigh Studies}

The preprocessing of the data consisted of firstly computing the daily mean speeds. The daily mean speed, $v_{m}$, was obtained by using equation (1): 


$$
v_{m}=\frac{1}{5} \sum_{i=1}^{5} v_{i}
$$

where $v_{m}$ is the daily mean and $v_{i}$ is the wind speed at time steps of 3 hours from 6 am to $6 \mathrm{pm}$, local time. These were then sequentially appended to give the weekly, monthly, etc, rows of daily means. The Weibull, Rayleigh, some other statistics and power density studies were carried out on these mean wind speeds.

\subsubsection{Wind Direction (Wind Rose Plots)}

In order to obtain information about the wind directions and classes from the five double columns (wind speed and direction, each) of the wind data per day, each was appended sequentially day after day through each week to months and to the rest of each year. This enabled the determination of average directions and classes per period (time of day) per month or per year. Finally, for each day, the pairs of data (direction and wind speed) per period were again appended so as to form two columns (of 5 rows) per day; through the weeks, months, years and for the continuous seven years. The wind rose Matlab program was applied on these columned data to eventually obtain the directions and mean wind speeds per class for the chosen period or duration of studies.

\section{Estimation of Wind Potential}

The theoretical available power, $P_{v}$, at each wind speed $v$ is given by

$$
P_{v}=\frac{1}{2} \rho A v^{3}
$$

where $\mathrm{A}$ is the rotor swept area and $\rho$ is the air density. Thus, power is about cubes of wind speed. The power density is defined by power per unit area. The air density is taken as a constant at $1.225 \mathrm{~kg} / \mathrm{m} 3$ for the simulations in this work. The power per unit area transported by a fluid system is related to the cube of the fluid speed, Kamau, Kinyua, Gathua (2010). Hence, for the spectrum of wind speeds, the total power density at an observation site is given by

$$
P_{d}=\frac{1}{2} \rho\left[\int_{0}^{\infty} v^{3} f(v) d v\right]
$$

where $f(v)$ is the probability density distribution, PDF, of wind speed. Its forms are determined by the probability distribution that best fits the wind regime. For simple PDFs, such as the Weibull or Rayleigh distributions, equation (3) can be solved analytically for their various parameters.

\section{Modeling and Evaluation Techniques of Wind Speed}

There are many probability distributions or density functions available, but not all are suitable for fitting wind speed. The statistical distributions included in this research are the Weibull and the Rayleigh distributions because most wind regimes in the world almost accurately are modeled by these two models.

\subsection{Weibull Model}

\subsubsection{Determination of the Weibull Parameters}

Rahbari, Vafaeipour, Fazelpour, Feidt, Rosen (2014) determined that the Weibull distribution is a very appropriate model fit in many situations. The Weibull function has much flexibility and simplicity and provides a logical fit to experimental data when applying to wind data as given in G. Johnson (2006). Equation (4) represents the 2-parameter Weibull probability function with the dimensionless shape parameter, $k$ and scale parameters, c, measured in $\mathrm{m} / \mathrm{s}$.

$$
F_{c, k}(v)= \begin{cases}1-\exp \left[-\left(\frac{v}{c}\right)^{k}\right] & \text { for } v \geq 0 \\ 0 & \text { for } v<0\end{cases}
$$

where $c>0$ and $k>0$.

The Weibull PDF is derived from its CDF and has the form:

$$
f_{c, k}(v)=F_{c, k}^{\prime}(v)=\frac{d}{d x} F_{c, k}(v)=\frac{k}{c}\left(\frac{v}{k}\right)^{k-1} \exp \left[-\left(\frac{v}{k}\right)^{k}\right],
$$

The $\mathrm{m}^{\text {th }}$ moment of the Weibull distribution provides a means of analytically determining some of its statistics, as earlier mentioned. Hence, for example, from its general $\mathrm{m}^{\text {th }}$ moment equation (6), the mean can be obtained as in equation (7). 


$$
E\left(v^{m}\right)=c^{m} \Gamma(1+m / c),
$$

where $\Gamma($.$) represents the gamma function. The standard deviation is derived from equation (8).$

Thus the mean $(\mathrm{m}=1)$ and variance $(\mathrm{m}=2)$ are given by equations $(7)$ and $(8)$, respectively.

$$
\begin{gathered}
E(v)=c \Gamma(1+1 / k), \\
\operatorname{var}(v)=c^{2}\left[\Gamma(1+2 / k)-\{1+1 / k\}^{2}\right],
\end{gathered}
$$

The standard deviation used in this work is simply the square root of equation (8).

Both the Weibull and Rayleigh models for the power density make use of $\mathrm{k}$ and $\mathrm{c}$, whereas for the Rayleigh function, $c$ is replaced by $b$. Hence, they have to be determined in order to model the power density in accordance with their respective density distributions.

Numerical techniques are the most used methods for the determination of the shape parameter, $\mathrm{k}$ and finally, the scale parameter, c, of the Weibull probability density function. Comparing 7 different methods, Paulo, de Sousa, de Andrade, da Silva (2012) determined that the most accurate values and Weibull fittings were observed on methods applying iterative routines on their more complex non-close form mathematical expressions.

The maximum likelihood estimation procedure for the 2-parameter Weibull function in equation (9), Azad, Rasul, Yusaf (2014) has been an extensively used method for estimating the parameters of the Weibull distribution due to, among many others, this particular desirable property. The commonly used procedure to determine $\mathrm{k}$ is the Newton-Raphson routine on equation (9):

$$
\frac{\sum_{i=1}^{n} x_{i}{ }^{k_{j}} \ln x_{i}}{\sum_{i=1}^{n} x_{i}^{k_{j}}}-\frac{1}{k_{j}}-\frac{1}{n} \sum_{i=1}^{n} \ln x_{i}=0
$$

$\mathrm{c}$ is then obtained by substituting $\mathrm{k}$ in equation (10):

$$
c=\frac{\sum_{i=1}^{n} x_{i}^{k}}{n}
$$

where $\mathrm{n}$ is the length of data.

\subsubsection{Weibull Power density Model}

The expected monthly or annual wind power density per unit area, $P_{W}$, of a site based on a Weibull probability density function, can be expressed as given by Bhattaracharya and Bhattacharjee (2010) in equation (11):

$$
P_{W}=\frac{1}{2} \rho c^{3} \Gamma(1+3 / k)
$$

The parameters $k$ and $c$ are related to the mean wind speed $v_{m}$ through

$$
c=\frac{v_{m}}{\Gamma(1+1 / k)}
$$

\subsection{Rayleigh Model}

The Rayleigh distribution is a special case of the Weibull distribution where the shape factor $\mathrm{k}$ is set to 2 . Its CDF and PDF, Gupta and Biswas (2010), are determined by equations (13) and (14), respectively.

$$
F(v)=1-\exp \left(-\frac{1}{2}\left(\frac{v}{b}\right)^{2}\right)
$$

And its probability density by

$$
f(v)=\frac{v}{b^{2}} \exp \left(-\frac{1}{2}\left(\frac{v}{b}\right)^{2}\right)
$$

where $b$, in $\mathrm{m} / \mathrm{s}$, is its scale parameter. As earlier mentioned, it is the counterpart of the scale parameter, $\mathrm{c}$, of the Weibull scale parameter.

\subsubsection{Rayleigh Power Density Model}

Putting $\mathrm{k}=2$ in equation (12) and finally in equation (11), we obtain the Rayleigh power density model; given by:

$$
P_{R}=\frac{3}{\pi} \rho v_{m}
$$




\section{Goodness-of-Fit (gof) Tests}

In order to deduce the degree of convergence of the various distributions to the actual measured data, the following three tests were performed on each of the probability distribution functions; namely $\mathrm{R}^{2}$, rmse and $\mathrm{X}^{2}$.

\subsection{The Coefficient of Determination (COD or $R^{2}$ )}

The $\mathrm{R}^{2}$, as provided in Carillo, Cidras, Diaz-Dorado, Obando-Montano (2014) is one of the best probability distribution hypothesis tests because of its quantification of the correlation between observed and predicted probabilities and is given by:

$$
R^{2}=1-\frac{\sum_{i=1}^{N}\left(X_{i}-x_{i}\right)^{2}}{\sum_{i=1}^{N}\left(X_{i}-\bar{X}\right)^{2}}
$$

The larger the value of $R^{2}$, the better is the fit of the model under consideration.

\subsection{The Root Mean Square Error}

The root mean square error is given by Abbas et al. (2012) as:

$$
\operatorname{RMSE}=\sqrt{\frac{1}{N} \sum_{i=1}^{N}\left(X_{i}-x_{i}\right)^{2}},
$$

where $X_{i}, x_{i}$ and $\bar{X}$, in $\mathrm{m} / \mathrm{s}$, in equations (16) and (17) are the observed, estimated and mean of the data, respectively.

\subsection{The Minimum Chi Square Method}

The Chi-Square method is used for testing the predicted against the actual wind distribution. The least determined value, among the distributions, on this model, normally chooses it as the best probability representative candidate. In Abbas et al. (2012) the Chi-square $\chi^{2}$ is equally given by

$$
\chi^{2}=\sum \frac{\sum_{i}^{k}\left(O_{i}-E_{i}\right)^{2}}{E_{i}}
$$

where Oi, Ei and $\mathrm{k}$ are the observed, expected frequencies and $\mathrm{k}$ the number of bins.

The least value of RMSE and $\chi^{2}$ indicates a better fit of the model.

\section{Results and Discussions}

In this study, we used Matlab R2013b and Microsoft Excel 2010 for all simulations and calculations.

Table 1 shows the simulation results carried on some of the afore mentioned equations on the yearly mean speeds for the variously concerned periods of measurement.

The following observations may be extracted from the table:

(i) The gof results (higher R2, lower rmse and X2, in each case) overwhelmingly show that the Weibull model better fits the wind regime than the Rayleigh model.

(ii) The mean, M, speeds are all less than $3.2 \mathrm{~m} / \mathrm{s}$. Good wind energy exploitative turbines have a cut-in wind speeds of more than $3.5 \mathrm{~m} / \mathrm{s}$.

(iii) The standard deviations, SD, are low indicating low amplitude of stochastic oscillations about the mean and are consequently almost stationary and, hence, reliable.

(iv) The shape parameter, $\mathrm{k}$, is always greater than the scale parameter, $\mathrm{c}$. This inadvertently affects the value of power density as evidenced in equation (11).

(v) The theoretical power densities, Pd, are very low and always almost identical with the model predictions Pw, of the Weibull model, but, both, are always less than that of the Rayleigh model, $\mathrm{P}_{\mathrm{R}}$. 
Table 1. Results of simulations for the parameters, statistics and power density on yearly means, and duration, for the two models

\begin{tabular}{|c|c|c|c|c|c|c|c|c|c|c|c|}
\hline Year & $\begin{array}{c}\text { PDF } \\
\text { model }\end{array}$ & $\begin{array}{c}M \\
(\mathrm{~m} / \mathrm{s})\end{array}$ & $\begin{array}{c}\mathrm{SD} \\
(\mathrm{m} / \mathrm{s})\end{array}$ & $\mathrm{k}$ & $\begin{array}{c}\mathrm{c} \\
(\mathrm{m} / \mathrm{s})\end{array}$ & rmse & $\mathrm{R} 2$ & $\mathrm{X} 2$ & $\begin{array}{c}\mathrm{Pb} \\
(\mathrm{W} / \mathrm{m} 2)\end{array}$ & $\begin{array}{c}\mathrm{PW} \\
(\mathrm{W} / \mathrm{m} 2)\end{array}$ & $\begin{array}{c}\text { PR } \\
(\mathrm{W} / \mathrm{m} 2)\end{array}$ \\
\hline \multirow{2}{*}{2007} & Weibull & \multirow{2}{*}{2.6} & \multirow{2}{*}{0.6} & 4.4 & 2.9 & 0.0414 & 0.9958 & 0.0033 & \multirow{2}{*}{11.8} & \multirow{2}{*}{11.9} & \multirow{2}{*}{19.0} \\
\hline & Rayleigh & & & 2.0 & 1.9 & 0.1329 & 0.9561 & 0.0338 & & & \\
\hline \multirow{2}{*}{2008} & Weibull & \multirow{2}{*}{2.8} & \multirow{2}{*}{0.7} & 4.5 & 3.1 & 0.0353 & 0.9967 & 0.0026 & \multirow{2}{*}{15.3} & \multirow{2}{*}{15.4} & \multirow{2}{*}{24.8} \\
\hline & Rayleigh & & & 2.0 & 2.1 & 0.1373 & 0.9495 & 0.0385 & & & \\
\hline \multirow{2}{*}{2009} & Weibull & \multirow{2}{*}{2.7} & \multirow{2}{*}{0.7} & 4.2 & 3.0 & 0.0395 & 0.9962 & 0.0029 & \multirow{2}{*}{14.0} & \multirow{2}{*}{14.1} & \multirow{2}{*}{22.2} \\
\hline & Rayleigh & & & 2.0 & 2.0 & 0.1246 & 0.9623 & 0.0289 & & & \\
\hline \multirow{2}{*}{2010} & Weibull & \multirow{2}{*}{2.4} & \multirow{2}{*}{0.7} & 3.8 & 2.6 & 0.0315 & 0.9976 & 0.0019 & \multirow{2}{*}{9.2} & \multirow{2}{*}{9.2} & \multirow{2}{*}{14.0} \\
\hline & Rayleigh & & & 2.0 & 1.7 & 0.0980 & 0.9766 & 0.0181 & & & \\
\hline \multirow{2}{*}{2011} & Weibull & \multirow{2}{*}{2.1} & \multirow{2}{*}{0.6} & 3.5 & 2.4 & 0.0491 & 0.9946 & 0.0042 & \multirow{2}{*}{6.9} & \multirow{2}{*}{7.0} & \multirow{2}{*}{10.3} \\
\hline & Rayleigh & & & 2.0 & 1.6 & 0.0984 & 0.9783 & 0.0170 & & & \\
\hline \multirow{2}{*}{2012} & Weibull & \multirow{2}{*}{2.3} & \multirow{2}{*}{0.5} & 4.7 & 2.5 & 0.0512 & 0.9944 & 0.0045 & \multirow{2}{*}{7.9} & \multirow{2}{*}{8.2} & 133 \\
\hline & Rayleigh & & & 2.0 & 1.7 & 0.1507 & 0.9505 & 0.0391 & & & 15.5 \\
\hline 2013 & Weibull & 22 & 05 & 4.5 & 2.5 & 0.0486 & 0.9940 & 0.0046 & 75 & 76 & 122 \\
\hline 2013 & Rayleigh & 2.2 & 0.5 & 2.0 & 1.6 & 0.1363 & 0.9522 & 0.0360 & 1.5 & 1.0 & 12.2 \\
\hline $7 \mathrm{yrs}$ & Weibull & 2.5 & 0.7 & 3.8 & 2.7 & 0.0370 & 0.9971 & 0.0024 & 10.4 & 10.5 & 16.0 \\
\hline
\end{tabular}

Figure 2 shows, for visual comparison of fitness, the composite qualitative results of the simulations of the Weibull and the Rayleigh models for contiguous 7 years. With respect to the PDFs, the Weibull probability density function well fits the histogram, whereas the Rayleigh underestimates it. From the same figure and with respect to their CDFs, the Rayleigh equally demonstrates a radical departure of its curve from the empirical CDF or ECDF, while the Weibull CDF well fits it. Since in both situations, quantitative and qualitative, the Rayleigh function always dramatically demonstrates this lack of fitness or coincidence with the characteristics of the wind regime, henceforth the Rayleigh studies shall be discontinued. We, thus, where necessary, continue investigations only with the Weibull function.

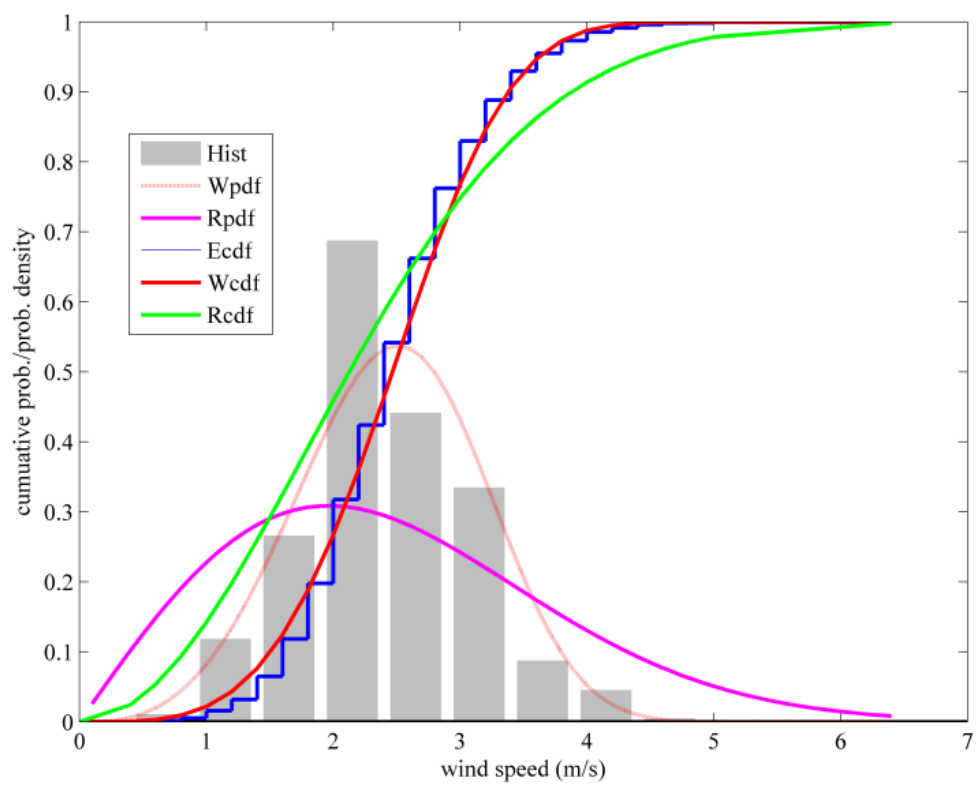

Figure 2. A composite figure of Weibull and Rayleigh PDFs, CDFs and ECDF for the 7 years 
We next carry out quantitative and qualitative simulations on monthly means for each year. The quantitative results are presented in Tables 2 to 9. Similar results, as in Table 1, are observed in these tables. Mean speeds are between 1.9 and $3.1 \mathrm{~m} / \mathrm{s}$, low SDs, always higher shape than the scale parameters, $\mathrm{Pb}$ and $\mathrm{P}_{\mathrm{W}}$ are almost same, albeit low. With respect to the gof results, the R2 values, in particular, also show that the wind regime is Weibull representative.

Table 2. Results of monthly mean wind speed simulations for the parameters, statistics and power densities for the year 2007

\begin{tabular}{llllllllll}
\hline 2007 & $\mathrm{M}(\mathrm{m} / \mathrm{s})$ & $\mathrm{STD}(\mathrm{m} / \mathrm{s})$ & $\mathrm{k}$ & $\mathrm{c}(\mathrm{m} / \mathrm{s})$ & $\mathrm{rmse}$ & $\mathrm{R} 2$ & $\mathrm{X} 2$ & $\mathrm{~Pb} \mathrm{~W} / \mathrm{m} 2$ & $\mathrm{WP}(\mathrm{W} / \mathrm{m} 2)$ \\
\hline Jan & 2.5 & 0.8 & 3.6 & 2.7 & 0.0488 & 0.9921 & 0.0049 & 10.9 & 10.9 \\
Feb & 2.9 & 0.5 & 6.5 & 3.1 & 0.0545 & 0.9897 & 0.0066 & 15.2 & 15.2 \\
Mar & 3.0 & 0.7 & 4.6 & 3.3 & 0.0755 & 0.9855 & 0.0101 & 17.6 & 17.8 \\
Apr & 2.7 & 0.6 & 5.3 & 3.0 & 0.0712 & 0.9873 & 0.0090 & 12.9 & 13.1 \\
May & 2.5 & 0.5 & 4.9 & 2.7 & 0.0838 & 0.9821 & 0.0124 & 9.4 & 9.6 \\
Jun & 2.3 & 0.7 & 3.6 & 2.6 & 0.0588 & 0.9896 & 0.0068 & 9.2 & 9.2 \\
Jul & 2.4 & 0.6 & 4.8 & 2.6 & 0.0640 & 0.9860 & 0.0090 & 9.0 & 9.0 \\
Aug & 2.5 & 0.5 & 5.1 & 2.7 & 0.0630 & 0.9895 & 0.0073 & 9.9 & 10.0 \\
Sept & 2.6 & 0.6 & 4.4 & 2.8 & 0.0645 & 0.9853 & 0.0089 & 11.5 & 11.6 \\
Oct & 2.5 & 0.7 & 4.1 & 2.8 & 0.0496 & 0.9919 & 0.0053 & 10.8 & 10.8 \\
Nov & 2.7 & 0.5 & 5.8 & 2.9 & 0.0860 & 0.9813 & 0.0133 & 11.7 & 11.9 \\
Dec & 2.7 & 0.7 & 4.4 & 3.0 & 0.0499 & 0.9914 & 0.0054 & 13.5 & 13.5 \\
\hline
\end{tabular}

Table 3. Results of monthly mean wind speed simulations for the parameters, statistics and power densities for the year 2008

\begin{tabular}{llllllllll}
\hline 2008 & $\mathrm{M}(\mathrm{m} / \mathrm{s})$ & $\mathrm{SD}(\mathrm{m} / \mathrm{s})$ & $\mathrm{k}$ & $\mathrm{c}(\mathrm{m} / \mathrm{s})$ & $\mathrm{rmse}$ & $\mathrm{R} 2$ & $\mathrm{X} 2$ & $\mathrm{~Pb}(\mathrm{~W} / \mathrm{m} 2)$ & $\mathrm{PW}(\mathrm{W} / \mathrm{m} 2)$ \\
\hline Jan & 2.5 & 0.5 & 6.1 & 2.7 & 0.0693 & 0.9866 & 0.0091 & 9.9 & 9.9 \\
Feb & 3.0 & 0.7 & 5.2 & 3.2 & 0.0439 & 0.9944 & 0.0038 & 17.0 & 17.0 \\
Mar & 3.1 & 0.7 & 5.1 & 3.4 & 0.0715 & 0.9834 & 0.0107 & 19.5 & 19.8 \\
Apr & 2.9 & 0.6 & 5.0 & 3.2 & 0.0625 & 0.9893 & 0.0073 & 15.8 & 16.0 \\
May & 2.8 & 0.6 & 4.5 & 3.0 & 0.0857 & 0.9822 & 0.0126 & 14.0 & 14.3 \\
Jun & 2.8 & 0.8 & 4.4 & 3.1 & 0.0440 & 0.9942 & 0.0040 & 15.2 & 15.1 \\
Jul & 2.9 & 0.8 & 4.0 & 3.2 & 0.0619 & 0.9882 & 0.0077 & 17.4 & 17.6 \\
Aug & 3.0 & 0.8 & 4.4 & 3.3 & 0.0430 & 0.9944 & 0.0037 & 17.6 & 17.4 \\
Sept & 2.6 & 0.6 & 5.0 & 2.9 & 0.0674 & 0.9844 & 0.0099 & 12.0 & 11.9 \\
Oct & 2.8 & 0.6 & 5.4 & 3.0 & 0.0723 & 0.9853 & 0.0100 & 13.5 & 13.6 \\
Nov & 2.9 & 0.7 & 5.0 & 3.2 & 0.0602 & 0.9902 & 0.0069 & 15.7 & 15.7 \\
Dec & 2.8 & 0.8 & 4.1 & 3.1 & 0.0415 & 0.9952 & 0.0033 & 15.2 & 15.2 \\
\hline
\end{tabular}


Table 4. Results of monthly mean wind speed simulations for the parameters, statistics and power densities for the year 2009

\begin{tabular}{llllllllll}
\hline 2009 & $\mathrm{M}(\mathrm{m} / \mathrm{s})$ & $\mathrm{SD}(\mathrm{m} / \mathrm{s})$ & $\mathrm{k}$ & $\mathrm{c}(\mathrm{m} / \mathrm{s})$ & $\mathrm{rmse}$ & $\mathrm{R} 2$ & $\mathrm{X} 2$ & $\mathrm{~Pb}(\mathrm{~W} / \mathrm{m} 2)$ & $\mathrm{PW}(\mathrm{W} / \mathrm{m} 2)$ \\
\hline Jan & 3.1 & 0.6 & 5.6 & 3.3 & 0.0587 & 0.9909 & 0.0064 & 18.5 & 18.7 \\
Feb & 3.1 & 0.7 & 4.8 & 3.4 & 0.0578 & 0.9897 & 0.0068 & 19.8 & 19.8 \\
Mar & 3.3 & 0.8 & 4.5 & 3.6 & 0.0575 & 0.9909 & 0.0062 & 23.1 & 23.2 \\
Apr & 3.1 & 0.6 & 6.1 & 3.3 & 0.0518 & 0.9906 & 0.0058 & 18.3 & 18.2 \\
May & 2.8 & 0.5 & 6.7 & 3.0 & 0.0634 & 0.9859 & 0.0090 & 13.4 & 13.5 \\
Jun & 2.7 & 0.7 & 4.5 & 2.9 & 0.0579 & 0.9897 & 0.0069 & 12.6 & 12.8 \\
Jul & 2.8 & 0.6 & 5.6 & 3.0 & 0.0629 & 0.9861 & 0.0087 & 13.3 & 13.2 \\
Aug & 2.6 & 0.7 & 4.2 & 2.8 & 0.0691 & 0.9859 & 0.0093 & 11.6 & 11.6 \\
Sept & 2.2 & 0.6 & 3.9 & 2.5 & 0.0677 & 0.9885 & 0.0082 & 7.6 & 7.8 \\
Oct & 2.5 & 0.7 & 3.9 & 2.7 & 0.0768 & 0.9842 & 0.0107 & 10.5 & 10.6 \\
Nov & 2.4 & 0.5 & 5.2 & 2.6 & 0.0789 & 0.9825 & 0.0118 & 9.1 & 9.3 \\
Dec & 2.4 & 0.7 & 4.2 & 2.7 & 0.0494 & 0.9926 & 0.0050 & 9.9 & 9.9 \\
\hline
\end{tabular}

Table 5. Results of monthly mean wind speed simulations for the parameters, statistics and power densities for the year 2010

\begin{tabular}{llllllllll}
\hline 2010 & $\mathrm{M}(\mathrm{m} / \mathrm{s})$ & $\mathrm{SD}(\mathrm{m} / \mathrm{s})$ & $\mathrm{k}$ & $\mathrm{c}(\mathrm{m} / \mathrm{s})$ & $\mathrm{rmse}$ & $\mathrm{R} 2$ & $\mathrm{X} 2$ & $\mathrm{~Pb}(\mathrm{~W} / \mathrm{m} 2)$ & $\mathrm{PW}(\mathrm{W} / \mathrm{m} 2)$ \\
\hline Jan & 2.4 & 0.6 & 4.8 & 2.6 & 0.0539 & 0.9917 & 0.0055 & 9.2 & 9.1 \\
Feb & 2.6 & 0.6 & 5.4 & 2.8 & 0.0603 & 0.9888 & 0.0076 & 11.1 & 11.1 \\
Mar & 2.5 & 0.8 & 3.6 & 2.8 & 0.0619 & 0.9854 & 0.0092 & 11.9 & 11.7 \\
Apr & 2.7 & 0.6 & 5.0 & 3.0 & 0.0607 & 0.9888 & 0.0074 & 12.8 & 12.9 \\
May & 2.4 & 0.6 & 4.7 & 2.6 & 0.0531 & 0.9911 & 0.0059 & 8.7 & 8.6 \\
Jun & 2.4 & 0.6 & 4.1 & 2.6 & 0.0549 & 0.9915 & 0.0058 & 8.9 & 9.0 \\
Jul & 2.6 & 0.7 & 3.7 & 2.9 & 0.0645 & 0.9870 & 0.0086 & 12.2 & 12.4 \\
Aug & 2.3 & 0.5 & 4.9 & 2.5 & 0.0628 & 0.9886 & 0.0078 & 7.5 & 7.5 \\
Sept & 1.9 & 0.6 & 3.8 & 2.1 & 0.0591 & 0.9892 & 0.0070 & 4.8 & 4.8 \\
Oct & 1.9 & 0.6 & 3.2 & 2.1 & 0.0684 & 0.9870 & 0.0086 & 5.2 & 5.2 \\
Nov & 2.3 & 0.7 & 3.5 & 2.5 & 0.0619 & 0.9897 & 0.0071 & 8.5 & 8.5 \\
Dec & 2.4 & 0.7 & 3.6 & 2.6 & 0.0789 & 0.9797 & 0.0127 & 9.6 & 9.7 \\
\hline
\end{tabular}

Table 6. Results for monthly mean wind speed simulations for the parameters, statistics and power densities for the year 2011

\begin{tabular}{lllllcccll}
\hline 2011 & $\mathrm{M}(\mathrm{m} / \mathrm{s})$ & $\mathrm{SD}(\mathrm{m} / \mathrm{s})$ & $\mathrm{k}$ & $\mathrm{c}(\mathrm{m} / \mathrm{s})$ & $\mathrm{rmse}$ & $\mathrm{R} 2$ & $\mathrm{X} 2$ & $\mathrm{~Pb}(\mathrm{~W} / \mathrm{m} 2)$ & $\mathrm{PW}(\mathrm{W} / \mathrm{m} 2)$ \\
\hline Jan & 2.3 & 0.7 & 3.4 & 2.5 & 0.1052 & 0.9728 & 0.0184 & 8.6 & 8.8 \\
Feb & 2.8 & 0.7 & 4.6 & 3.0 & 0.1088 & 0.9661 & 0.0222 & 14.1 & 14.3 \\
Mar & 2.5 & 0.7 & 4.2 & 2.7 & 0.0591 & 0.9897 & 0.0068 & 10.6 & 10.7 \\
Apr & 2.2 & 0.6 & 3.8 & 2.4 & 0.0643 & 0.9871 & 0.0083 & 7.6 & 7.6 \\
May & 2.2 & 0.7 & 3.4 & 2.5 & 0.0536 & 0.9920 & 0.0054 & 8.1 & 8.1 \\
Jun & 2.0 & 0.5 & 4.3 & 2.2 & 0.0545 & 0.9919 & 0.0057 & 5.8 & 5.8 \\
Jul & 1.9 & 0.5 & 4.5 & 2.1 & 0.0533 & 0.9913 & 0.0058 & 4.7 & 4.6 \\
Aug & 1.8 & 0.5 & 4.0 & 2.0 & 0.0494 & 0.9923 & 0.0053 & 4.0 & 4.0
\end{tabular}




\begin{tabular}{llllllllll} 
Sept & 1.9 & 0.5 & 3.9 & 2.1 & 0.0652 & 0.9886 & 0.0079 & 4.9 & 5.0 \\
Oct & 2.0 & 0.5 & 4.6 & 2.2 & 0.0822 & 0.9830 & 0.0115 & 5.5 & 5.6 \\
Nov & 1.9 & 0.4 & 4.5 & 2.0 & 0.0657 & 0.9881 & 0.0082 & 4.2 & 4.2 \\
Dec & 2.0 & 0.4 & 5.3 & 2.2 & 0.0824 & 0.9799 & 0.0128 & 5.4 & 5.5 \\
\hline
\end{tabular}

Table 7. Results on monthly mean wind speed simulations for the parameters, statistics and power densities for the year 2012

\begin{tabular}{llllllllll}
\hline 2012 & $\mathrm{M}(\mathrm{m} / \mathrm{s})$ & $\mathrm{SD}(\mathrm{m} / \mathrm{s})$ & $\mathrm{k}$ & $\mathrm{c}(\mathrm{m} / \mathrm{s})$ & $\mathrm{rmse}$ & $\mathrm{R} 2$ & $\mathrm{X} 2$ & $\mathrm{~Pb}(\mathrm{~W} / \mathrm{m} 2)$ & $\mathrm{PW}(\mathrm{W} / \mathrm{m} 2)$ \\
\hline Jan & 2.1 & 0.5 & 5.2 & 2.3 & 0.0722 & 0.9860 & 0.0094 & 5.9 & 5.9 \\
Feb & 2.4 & 0.5 & 5.8 & 2.6 & 0.0781 & 0.9807 & 0.0125 & 9.1 & 9.2 \\
Mar & 2.2 & 0.4 & 5.6 & 2.3 & 0.0830 & 0.9802 & 0.0132 & 6.3 & 6.3 \\
Apr & 2.3 & 0.4 & 5.4 & 2.5 & 0.0835 & 0.9815 & 0.0126 & 7.7 & 7.8 \\
May & 2.3 & 0.5 & 5.8 & 2.5 & 0.0583 & 0.9900 & 0.0068 & 7.6 & 7.6 \\
Jun & 2.5 & 0.6 & 4.7 & 2.7 & 0.0658 & 0.9882 & 0.0082 & 9.7 & 9.7 \\
Jul & 2.4 & 0.5 & 6.4 & 2.6 & 0.0677 & 0.9854 & 0.0095 & 8.8 & 8.8 \\
Aug & 2.5 & 0.6 & 3.8 & 2.7 & 0.1050 & 0.9697 & 0.0196 & 10.3 & 10.7 \\
Sept & 2.3 & 0.5 & 4.0 & 2.5 & 0.1454 & 0.9455 & 0.0342 & 8.2 & 8.7 \\
Oct & 2.4 & 0.4 & 5.4 & 2.5 & 0.0858 & 0.9792 & 0.0139 & 8.2 & 8.4 \\
Nov & 2.2 & 0.5 & 5.2 & 2.4 & 0.0732 & 0.9853 & 0.0100 & 7.0 & 7.0 \\
Dec & 2.2 & 0.4 & 6.4 & 2.3 & 0.0813 & 0.9759 & 0.0149 & 6.4 & 6.5 \\
\hline
\end{tabular}

Table 8. Table Results of monthly mean wind speed simulations for the parameters, statistics and power densities for the year 2013

\begin{tabular}{llllllclll}
\hline 2013 & $\mathrm{M}(\mathrm{m} / \mathrm{s})$ & $\mathrm{SD}(\mathrm{m} / \mathrm{s})$ & $\mathrm{k}$ & $\mathrm{c}(\mathrm{m} / \mathrm{s})$ & $\mathrm{rmse}$ & $\mathrm{R} 2$ & $\mathrm{X} 2$ & $\mathrm{~Pb}(\mathrm{~W} / \mathrm{m} 2)$ & $\mathrm{PW}(\mathrm{W} / \mathrm{m} 2)$ \\
\hline Jan & 2.2 & 0.4 & 5.2 & 2.3 & 0.0930 & 0.9802 & 0.0140 & 6.4 & 6.5 \\
Feb & 2.7 & 0.5 & 6.7 & 2.8 & 0.0702 & 0.9831 & 0.0105 & 11.5 & 11.5 \\
Mar & 2.5 & 0.6 & 4.5 & 2.7 & 0.0717 & 0.9831 & 0.0106 & 9.8 & 10.0 \\
Apr & 2.2 & 0.6 & 4.1 & 2.5 & 0.0586 & 0.9881 & 0.0077 & 7.7 & 7.6 \\
May & 2.4 & 0.6 & 4.6 & 2.7 & 0.0750 & 0.9856 & 0.0101 & 9.4 & 9.5 \\
Jun & 2.3 & 0.5 & 5.1 & 2.5 & 0.0523 & 0.9908 & 0.0060 & 7.9 & 7.9 \\
Jul & 2.2 & 0.4 & 6.1 & 2.4 & 0.0799 & 0.9797 & 0.0134 & 6.9 & 6.9 \\
Aug & 2.1 & 0.5 & 4.1 & 2.3 & 0.0875 & 0.9805 & 0.0136 & 5.9 & 6.0 \\
Sept & 2.1 & 0.5 & 4.7 & 2.3 & 0.0631 & 0.9884 & 0.0078 & 6.0 & 6.0 \\
Oct & 2.2 & 0.5 & 4.7 & 2.4 & 0.0606 & 0.9903 & 0.0069 & 7.1 & 7.1 \\
Nov & 2.1 & 0.5 & 4.9 & 2.3 & 0.0696 & 0.9853 & 0.0100 & 6.1 & 6.1 \\
Dec & 2.1 & 0.4 & 5.4 & 2.2 & 0.0778 & 0.9799 & 0.0128 & 5.5 & 5.5 \\
\hline
\end{tabular}

We choose only one year, year 2010, to demonstrate the graphical presentations of the qualitative simulations results of the monthly mean wind speed. Figure 3 shows that the PDF curves for each month for that year are almost bell-shaped, like for a normal distribution; depicting high shape parameter values. Figure 4 shows the corresponding CDFs and are relatively steep, which still validates the (high) range values of the shape parameter. 


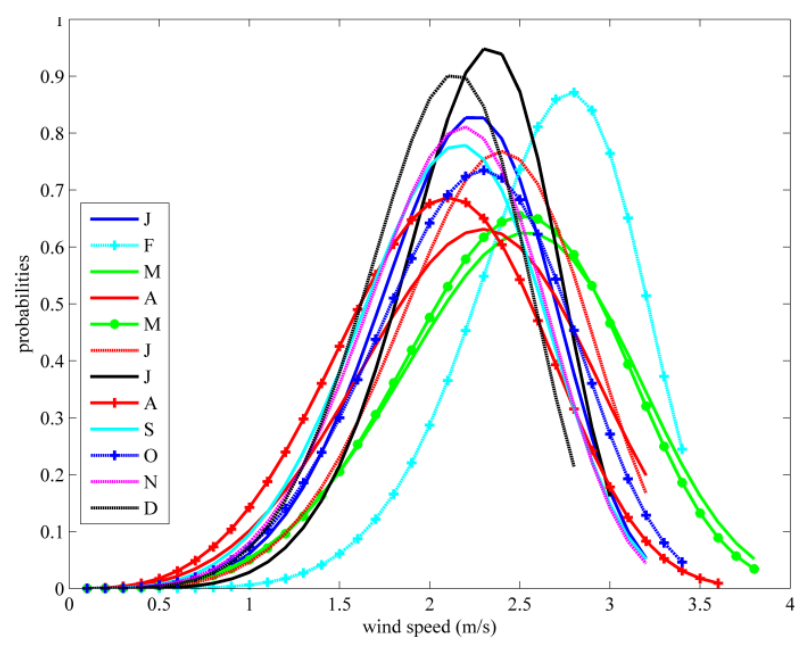

Figure 3. Monthly Weibull PDFs for the year 2010

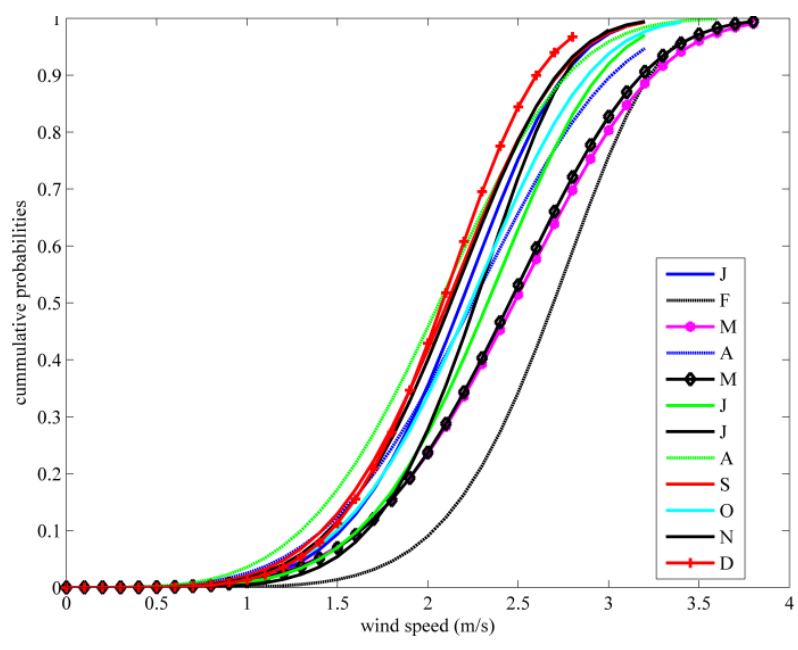

Figure 4. Monthly Weibull CDFs for the year 2010

Figures 5 to 8 show figures of sampled wind roses and their bins for the duration of 7 years, year 2013, at 6am and at $3 \mathrm{pm}$, respectively. It is observed in all the figures that all the wind directions fall within the first quadrants, NE. The North was chosen in this work as the reference. In Figs. 5,6,8 the main direction from which the winds flow is $10^{\circ}$, and the yearly average have three discernible main directions with some high winds. For the winds at $6 \mathrm{am}$, Figure 7, there are only two main directions and with low wind speeds, as observed from the wind rose legend. Generally, it was observed that most calms occurred at $6 \mathrm{am}$; increasing gradually to a maxim at $3 \mathrm{pm}$ and falling again at $6 \mathrm{pm}$. However, the highest frequency of winds at $6 \mathrm{am}$ and $9 \mathrm{am}$ flow in angle $30^{\circ}$, albeit very low wind speeds. Studying the legends in general, it is observed that the highest wind speeds are between 8 and $9 \mathrm{~m} / \mathrm{s}$.

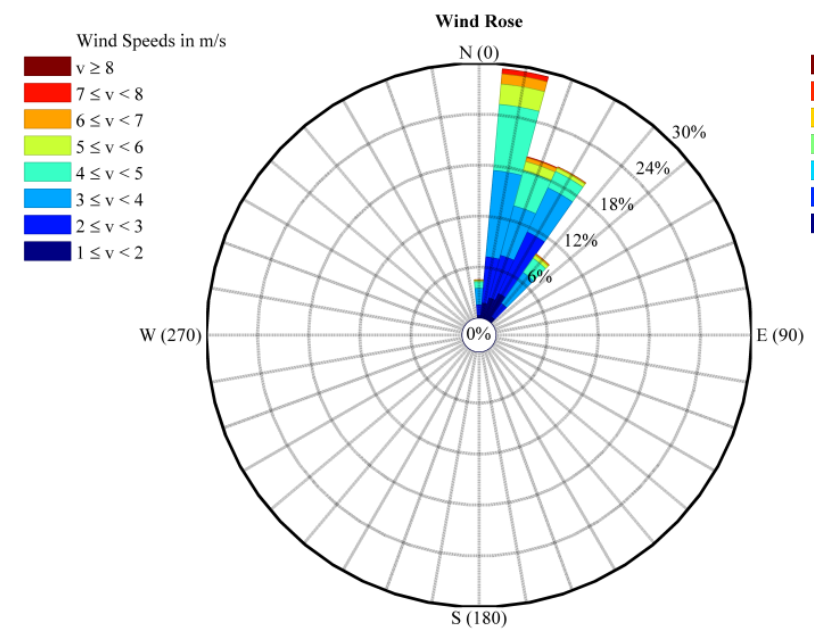

Figure 5. Wind Rose plot for seven years data

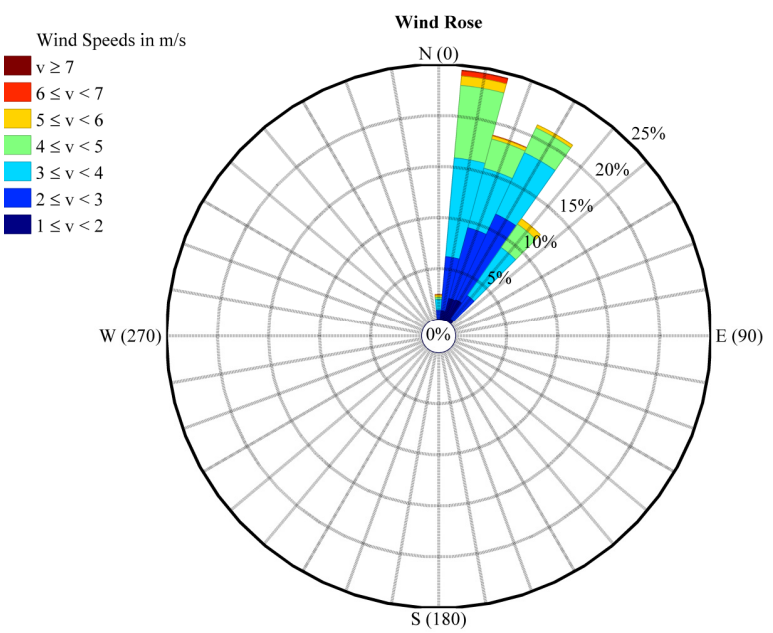

Figure 6. Wind Rose plot for the year 2013 


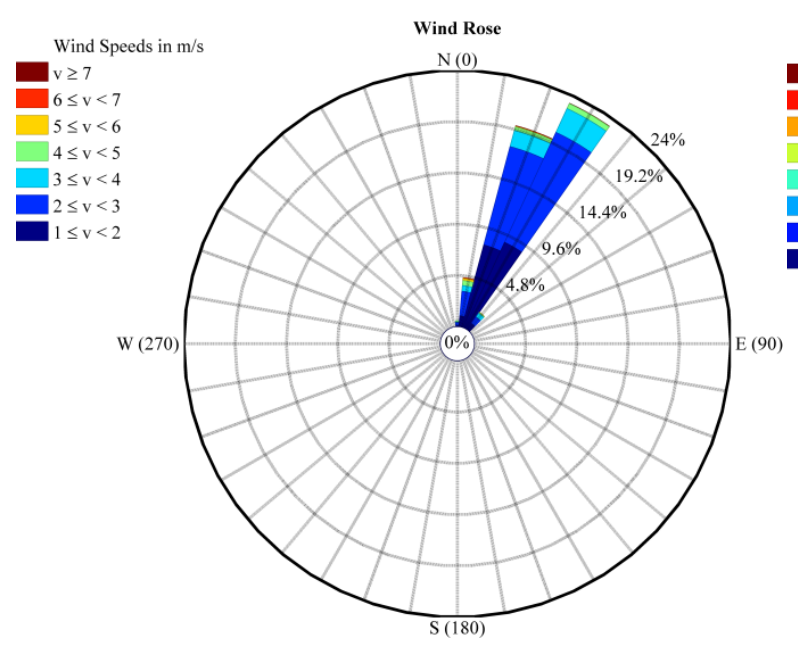

Figure 7. Wind Rose plot for at 6 am

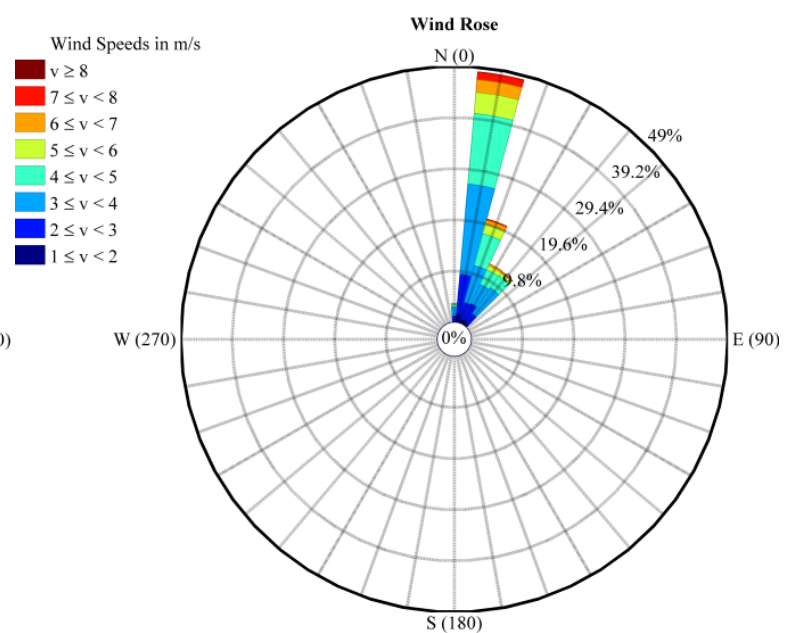

Figure 8. Wind Rose plot for at 3pm

From numerical calculations and binning of the various wind directions and classes, respectively, we corroborate the wind roses with only two tables; for year 2009 and at midday. All other results follow a similar pattern.

These numerical results were displayed to two decimal places because at only one decimal place, some values become visibly negligible but are indicated by wind rose plots.

Tables 9 and 10 show frequencies for each wind speed in each range and average directions, respectively. The frequencies are observed directly below each with speed range; to the right of first column, which is the average wind speed direction. The last column is the sum of the frequencies of each wind speed range for the average direction. It is observed from the two tables that (i) only angles $10^{\circ}, 20^{\circ}, 30^{\circ}$ and $40^{\circ}$ are represented, which are all first quadrant angles; thus validating the fact that all winds come from the NE. (ii) the highest frequency of the winds are at average direction of $10^{\circ}$. Below each wind range is the componential contribution of each range to each average wind speed direction. However, the last row shows the total frequency for which the wind speed is zero or calms.

From all the simulations, the highest frequency, (24.00\%), of calms were obtained in 2011 and lowest, (10.44\%), in 2008 . The highest frequency, $(50.10 \%)$, of calms were observed at $6 \mathrm{am}$ and the least, $(1.6 \%)$, at 12 noon.

Table 9. Wind speed bins, average directions, frequencies per direction and frequencies per speed bin for the year 2009

\begin{tabular}{|c|c|c|c|c|c|c|c|c|}
\hline Year: 2009 & & & Iind Spe & nterval ( & /Freque & & & Total \\
\hline Direction $\left({ }^{\circ}\right)$ & {$[1,2)$} & {$[2,3)$} & {$[3,4)$} & {$[4,5)$} & {$[5,6)$} & {$[6,7)$} & {$[7$, Inf) } & freq. \\
\hline 0 & 0.5 & 0.7 & 1.0 & 1.4 & 0.3 & 0.2 & 0.1 & 4.2 \\
\hline 10 & 2.5 & 6.5 & 9.9 & 9.0 & 3.2 & 2.0 & 0.9 & 33.9 \\
\hline 20 & 2.1 & 5.0 & 5.3 & 7.2 & 2.2 & 1.0 & 0.2 & 23.1 \\
\hline 30 & 3.8 & 7.2 & 4.3 & 2.5 & 0.5 & 0.1 & 0.0 & 18.5 \\
\hline 40 & 0.3 & 1.5 & 3.5 & 2.0 & 0.5 & 0.2 & 0.0 & 7.9 \\
\hline TOTAL & 9.2 & 20.8 & 24.0 & 22.1 & 6.8 & 3.5 & 1.2 & 87.6 \\
\hline Calms & & & & & & & & 12.4 \\
\hline
\end{tabular}


Table 10. Wind speed bins, average directions, frequencies per direction and frequencies per speed bin at midday

\begin{tabular}{llllllllll} 
Time: 12noon & \multicolumn{7}{c}{ Wind Speed Interval $(\mathrm{m} / \mathrm{s}) /$ Frequencies } & Total \\
\cline { 1 - 6 } Direction $\left(^{\circ}\right)$ & {$[1,2)$} & {$[2,3)$} & {$[3,4)$} & {$[4,5)$} & {$[5,6)$} & {$[6,7)$} & {$[7,8)$} & {$[8$, Inf $)$} & freq. \\
\hline 0 & 0.27 & 1.52 & 2.54 & 1.41 & 0.31 & 0.23 & 0.12 & 0.00 & 6.40 \\
10 & 2.07 & 5.94 & 15.15 & 11.28 & 5.43 & 1.99 & 1.21 & 0.00 & 43.07 \\
20 & 0.62 & 2.42 & 5.78 & 3.40 & 1.33 & 0.55 & 0.20 & 0.00 & 14.29 \\
30 & 0.82 & 4.30 & 8.43 & 3.48 & 0.59 & 0.20 & 0.04 & 0.04 & 17.88 \\
40 & 0.47 & 2.34 & 8.20 & 4.26 & 1.02 & 0.43 & 0.04 & 0.00 & 16.75 \\
TOTAL & 4.26 & 16.52 & 40.10 & 23.82 & 8.67 & 3.40 & 1.60 & 0.04 & 98.40 \\
Calms & & & & & & & & & 1.60 \\
\hline
\end{tabular}

\section{Conclusion}

We studied the Wind characteristics of Bafoussam airport, Cameroon, based on three-hourly wind speeds, measured five times a day starting at $6 \mathrm{am}$ local time and at a height of $10 \mathrm{~m}$. The speeds were determined using the Beaufort scale and in $\mathrm{m} / \mathrm{s}$. The gof results determine the Weibull PDF to be a good representative distribution function for the wind pattern of Bafoussam. Bafoussam is characterized by very low wind speeds whose means vary between 1.9 and $3.1 \mathrm{~m} / \mathrm{s}$ in all cases considered. Using the Theoretical and the Weibull power density formulations, it was observed that Bafoussam is a poor wind energy potential site with the highest value being $19.8 \mathrm{~W} / \mathrm{m} 2$ in March 2008 and the lowest being 4.0W/m2 in August 2011 using the Weibull power model. Either the Theoretical or the Weibull power could be used as their values were almost identical.

The Wind roses results showed, averagely, that all winds were from the NE (first quadrant), with a predominance at angle $10^{\circ}$ and some at $20^{\circ}$ and $30^{\circ}$, each year for the seven years and for the contiguous seven years. However, determining these directions during the periodic time steps, it was determined that most of winds came in at angle $30^{\circ}$ during the 6am and 9am time steps. The angles gradually changed to $10^{\circ}$ and $20^{\circ}$ for the last three measurements of the periods of the day. Also, the highest wind speeds were measured at $3 \mathrm{pm}$ and most calms were observed at 6am.

This study is imbued with some inherent shortcomings. The 3-hourly time steps greatly diminish the stochastic nature of wind speeds and directions at shorter sampling times. The Beaufort scale is equally generally subjective and, hence, less accurate. The height of evaluation of energy potential assumes zero surface roughness. A longer duration of data gives a more dependable picture about the average values of parameters at a site. Based on these assumptions and inadequacies, we thus provide the following recommendations for future studies at this site:

(i) Evaluations at higher heights using, at least, any of the power laws that take care of the effect of surface roughness.

(ii) Coming back after a considerable number of years for a longer duration of data that takes care of local (weather) changes and seasonality, hence, giving a more vivid picture about the average parameters described in this work.

(iii) The Weibull PDF clearly better fits the wind pattern than the Rayleigh model but could be inadequate compared with other probability density functions. Thus, further studies are recommended by applying the broader spectrum of probability density functions to determine that which actually best describes the wind regime at Bafoussam.

(iv) A higher sampling rate describes a better stochastic nature of wind directions and speeds than the average values in the 3-hourly time steps used in this study. Thus, a revisit is advised for the short duration measurement of wind speeds and direction with the newly installed instruments at the Bafoussam airport.

\section{Acknowledgement}

We wish to acknowledge and appreciate the authorities of the Bafoussam Airport for providing us with the data used in this work. 


\section{References}

Abbas, K., Alamgir, Khan, S. A., Ali, A., Khan, D. M., \& Khalil, U. (2012). Statistical Analysis of Wind Speed Data in Pakistan. World Applied Sciences Journal, 18(11), 1533-1539.

Adaramola, M. S., \& Oyewola, O. M. (2011). On wind speed pattern and energy potential in Nigeria. Energy Policy, 39, 2501-2506. http://dx.doi.org/10.1016/j.enpol.2011.02.016

Afungchui, D., \& Aban, C. E. (2014). Analysis of wind regimes for energy estimation in Bamenda, of the North West Region of Cameroon, based on the Weibull distribution. Revue des Energies Renouvelables, 17(1), 137-147.

Aynuar, U., \& Figen, B. (2008). A seasonal analysis of wind turbine characteristics and wind power potential in Manisa, Turkey. International Journal of Green Energy, 5(6), 466-479. http://dx.doi.org/10.1080/15435070802498101

Azad, A. K., Rasul, M. G., \& Yusaf, T. (2014). Statistical Diagnosis of the Best Weibull Methods for Wind Power Assessment for Agricultural Applications. Energies, 7, 3056-3085. http://dx.doi.org/10.3390/en7053056

Bhattaracharya, P., \& Bhattacharjee, R. (2010, Summer). Journal of Applied Quantitative Methods, 5(2).

Carillo, C., Cidras, J., Diaz-Dorado, E., \& Obando-Montano, A. F. (2014). An approach to determine the Weibull Parameters for wind Energy Analysis: The Case of Galicia (Spain). Energies, 7, 2676-2700. http://dx.doi.org/10.3390/en7042676

Google Earth Pro. (2013). Map of Bafoussam Town, Created 08/25/2015, V 7.1.2. 2041.

Gupta, R., \& Biswas, A. (2010, February). Wind analysis of silchar (Assam, India) by Rayleigh's and Weibull methods. Journal of Mechanical Engineering Research, 2(1), 10-24.

Johnson, G. (2006). Wind Energy Systems. Kansas State University, Manhattan, KS, USA.

Kamau, J. N., Kinyua, R., \& Gathua, J. K. (2010). 6 years of wind data for Marsabit, Kenya average over 14m/s at $100 \mathrm{~m}$ hub height; An analysis of the wind energy potential. Renewable Energy, 35(6), 1298-1302. http://dx.doi.org/10.1016/j.renene.2009.10.008

Kaoga, D. K., Danwe, R., Yamigno, S. D., \& Djongyang, N. (2014). Performance Analysis of Methods for Estimating Weibull Parameters for Wind Speed Distribution in the District of Maroua. Journal of Fundamental and Applied Sciences.

Kaoga, D. K., Djongyang, N., Doka, S. Y., \& Raidandi, D. (2014). Assessment of wind energy potential for small scale water pumping systems in the north region of Cameroon. International Journal of Basic and Applied Sciences, 3(1), 38-46.

Kaoga, D. K., Sergeb, D. Y., Raidandic, D., \& Djongyangd, N. (2014). Performance Assessment of Two-parameter Weibull Distribution Methods for Wind Energy Applications in the District of Maroua in Cameroon. International Journal of Sciences, Basic and Applied Research (IJSBAR), 17(1), 39-59.

Kaoga1, D. K., Raidandi, D., Djongyang, N., \& Doka, S. Y. (2014, March). Comparison of Five Numerical Methods for Estimating Weibull Parameters for Wind Energy Applications in the District of Kousseri. Cameroon, Asian Journal of Natural \& Applied Sciences, 3(1).

Nfah, E. M., Ngundamb, J. M., Vandenbergh, M., \& Schmid, J. (2008). Simulation of off-grid generation options for remote villages in Cameroon. Renewable Energy (Science Direct), 33(5), 1064-1072. http://dx.doi.org/10.1016/j.renene.2007.05.045

Paulo A. C. R., de Sousa, R. C., de Andrade, C. F., \& da Silva, M. E. V. (2012). Comparison of seven numerical methods for determining Weibull parameters for wind energy generation in the northeast region of Brazil. Applied Energy, 89, 395-400. http://dx.doi.org/10.1016/j.apenergy.2011.08.003

Rahbari, O., Vafaeipour, M., Fazelpour, F., Feidt, M., \& Rosen, M. A. (2014). Towards realistic designs of wind farm layouts: Application of a novel placement selector approach. Energy Conversion and Management, 81, 242-254. http://dx.doi.org/10.1016/j.enconman.2014.02.010

Safari, B., \& Gasore, J. (2010). A statistical investigation of wind characteristics and wind energy potential based on the Weibull and Rayleigh models in Rwanda. Renewable Energy, 35(12), 2874-2880. http://dx.doi.org/10.1016/j.renene.2010.04.032 
Sathyajith, M. (2006). Wind Energy: Fundamentals, Resource Analysis and Economics. Springer-Verlag Berlin Heidelberg, Netherlands.

Tchinda, R., \& Kaptouom, E. (2003). Wind energy in Adamaoua and North Cameroon provinces. Int J Energy Conver Manag, 44, 845-857. http://dx.doi.org/10.1016/S0196-8904(02)00092-4

Tchinda, R., Kendjio, J., Kaptouom, E., \& Njomo, D. (2014). Estimation of mean wind energy available in far north Cameroon. Energy Conversion and Management, Pergamon, 41, 1917-1929. http://dx.doi.org/10.1016/S0196-8904(00)00017-0

\section{Appendix}

The Matlab code used for the determination of the shape parameter using the Maximum Likelihood Method (MLM) through the Newton-Raphson routine.

$\%$ This Matlab code uses the Newton-Raphson routine, using the

$\%$ Maximum Likelihood Method to determines the Weibull shape parameter, $\mathrm{k}$,

$\%$ which is finally used to determine the scale parameter, c.

$\%$

$\%$ Program by Bawe Gerard Nfor, Jr, Department of Physics of Dschang, Cameroon

$\%$ October 2010

$\%==================$ START OF MLE $=====================$

$\mathrm{dx}=0.00005 ; \%$ step size

$\mathrm{k}=\mathrm{dx} ; \%$ initializing the $\mathrm{k}$ value

iter=1;

while $\mathrm{k}<7 \%$ maximum value of $\mathrm{k}$ for which to stop the iterations

$\mathrm{R}=\left(\operatorname{sum}\left(\left(\mathrm{x} .{ }^{\wedge} \mathrm{k}\right){ }^{*} \log (\mathrm{x})\right) / \operatorname{sum}\left(\mathrm{x} .{ }^{\wedge} \mathrm{k}\right)\right)-(1 / \mathrm{k})-(1 / \mathrm{n}) * \operatorname{sum}(\log (\mathrm{x}))$; \% the main function

$\mathrm{RR}($ iter $)=\mathrm{R} ; \%$ history of the $\mathrm{R}$ value at each iteration

$\mathrm{kk}($ iter $)=\mathrm{k} ; \%$ history of the $\mathrm{k}$ value at each iteration

$\mathrm{k}=\mathrm{k}+\mathrm{dx} ; \%$ next increment of the $\mathrm{k}$ value

iter=iter $+1 ; \%$ the last iteration

end

$\mathrm{kk}($ iter$)=\mathrm{k} ; \%$ extracting and displaying calculated $\mathrm{k}$ values: a column vector

$\mathrm{RR}($ iter$)=\mathrm{R} ; \%$ extracting and displaying calculated minimum values: column vector

$\mathrm{Lk}=$ length(kk); \% length of $\mathrm{k}$ values: check to see is equal to that of $\mathrm{R}$ values

$\mathrm{LR}=$ length(RR); \% length of minimum values: check to see that $=$ to that of $\mathrm{k}$

$\mathrm{T}=\left[\mathrm{RR}^{\prime}, \mathrm{kk}\right.$ ']; \% tabulate the history of calculated min values and corresponding $\mathrm{k}$ values

MinRvalue $=\min (\operatorname{abs}(\mathrm{RR})) ; \%$ the absolute minimum value of $\mathrm{R}$ that satisfies the stopping criteria

$[C, I]=\min (\operatorname{abs}(R R)) ; \%$ extract the index or position of the minimum value

$\mathrm{k}=\mathrm{kk}(\mathrm{I}) ; \%$ extract the value of $\mathrm{k}$ that corresponds with minimum value

$\mathrm{c}=\left(\operatorname{mean}\left(\mathrm{x} . \cdot^{\wedge} \mathrm{k}\right)\right)^{\wedge}(1 / \mathrm{k}) ; \%$ value and display scale parameter

c; $\%$ display scale parameter

$\mathrm{k} ; \%$ display shape parameter

$\mathrm{ck}=[\mathrm{c}, \mathrm{k}]$ 
\% Supplementary: determine the LogLikehood Profile

$\mathrm{L}=\mathrm{n}^{*} \log (\mathrm{k})-\mathrm{n}{ }^{*} \mathrm{c}{ }^{*} \log (\mathrm{k})+(\mathrm{k}-1){ }^{*} \operatorname{sum}(\log (\mathrm{x}))-\left(1 . /\left(\mathrm{c} .{ }^{\wedge} \mathrm{k}\right)\right)^{*} \operatorname{sum}\left(\mathrm{x} .{ }^{\wedge} \mathrm{k}\right)$;

$\%=======$ END OF MLE PARAMETER ESTIMATION FOR $\mathrm{k}$ and $\mathrm{c}=$

$\%$ If you ever use this code, please be honest enough give me due credits as

$\%$ being obtained from this article, following the

$\%$ journal citation formulation as specified by this journal, the JSD!

\section{Copyrights}

Copyright for this article is retained by the author(s), with first publication rights granted to the journal.

This is an open-access article distributed under the terms and conditions of the Creative Commons Attribution license (http://creativecommons.org/licenses/by/3.0/). 